\title{
DESENVOLVIMENTO DE UM CONSOLIDÔMETRO PNEUMÁTICO: MODELAGEM DA COMPACTAÇÃO, PENETROMETRIA E RESISTÊNCIA TÊNSIL DE AGREGADOS DE SOLO ${ }^{(1)}$
}

\author{
Getulio Coutinho Figueiredo ${ }^{(2)}$, Alvaro Pires da Silva ${ }^{(3)}$, Cássio \\ Antonio Tormena ${ }^{(4)}$, Neyde Fabíola Balarezo Giarola ${ }^{(5)}$, Sergio \\ Oliveira Moraes $^{(6)} \&$ Brivaldo Gomes de Almeida ${ }^{(7)}$
}

\begin{abstract}
RESUMO
A compactação é um dos processos responsáveis pela degradação física do solo que pode ocasionar a perda da sustentabilidade da produção agrícola. Assim, é fundamental dispor de estratégias instrumentais para quantificar as propriedades físicas que são influenciadas pela compactação e utilizadas para avaliar a qualidade do solo. Os objetivos deste trabalho foram: desenvolver um consolidômetro com propulsão pneumática de baixo custo; avaliar sua funcionalidade mediante estudo do comportamento compressivo de um Latossolo Vermelho distrófico de textura argilo-arenosa sob plantio direto; e avaliar o potencial de utilização da propulsão pneumática para determinações de resistência do solo à penetração (RP) e de resistência tênsil de agregados (RT). A avaliação do comportamento compressivo do solo foi realizada mediante curvas de compressão, utilizando amostras indeformadas, obtidas das posições de amostragem relativas à linha è è trelinha da cultura de aveia-preta. Nessas amostras, foram realizados ensaios de compressão uniaxial em condição de teor de água correspondente ao potencial mátrico de -10 $\mathrm{kPa}$, sendo determinados o índice de compressão (IC) e a
\end{abstract}

\footnotetext{
(1) Parte da Tese de doutorado do primeiro autor apresentada à Escola Superior de Agricultura "Luiz de Queiroz", Universidade de São Paulo - ESALQ/USP. Recebido para publicação em março 2010 e aprovado em dezembro 2010.

(2) Pós-Doutorando do Programa de Pós-Graduação em Solos e Nutrição de Plantas, Escola Superior de Agricultura "Luiz de Queiroz" - ESALQ/USP. Av. Pádua Dias 11 - Caixa Postal 09, CEP 13418-900 Piracicaba (SP). E-mail: figueiredo.gc@gmail.com

(3) Departamento de Ciência do Solo, ESALQ/USP. Bolsista do CNPq. E-mail: apisilva@esalq.usp.br

(4) Departamento de Agronomia, Universidade Estadual de Maringá - UEM. Av. Colombo 5790, CEP 87020-900 Maringá (PR). Bolsista do CNPq. E-mail: catormena@uem.br

(5) Departamento de Ciência do Solo e Engenharia Agrícola, Universidade Estadual de Ponta Grossa - UEPG. Av. General Carlos Cavalcanti 4748, CEP 84030-900 Ponta Grossa (PR). E-mail: neydef@uepg.br

(6) Departamento de Ciências Exatas, ESALQ/USP. E-mail: somoraes@esalq.usp.br

(7) Departamento de Agronomia, Universidade Federal Rural de Pernambuco - UFRPE. Av. Dom Manuel de Medeiros s/n, CEP 52171-900 Recife (PE). E-mail: brivaldo@depa.ufrpe.br
} 
pressão de preconsolidação $\left(\sigma_{\mathrm{p}}\right)$, bem como suas relações com outras propriedades físicas do solo. A RP foi determinada em amostras indeformadas de um Argissolo Vermelho-Amarelo distrófico de textura franco-arenosa sob citros. Para as determinações da RT foram utilizados agregados de dois solos: um Argissolo Acinzentado distrófico arênico coeso e um Argissolo Amarelo distrófico arênico. Os resultados mostram que a densidade do solo, antes do ensaio de compressão uniaxial, foi maior $(p<0,05)$ para a entrelinha da cultura de aveia-preta. A curva de compressão foi sensível às alterações estruturais do solo entre as posições de amostragem; a $\sigma_{\mathrm{p}}$ e o IC indicaram, respectivamente, maior capacidade de suporte de carga e menor suscetibilidade à compactação $(p<0,05)$ para a entrelinha da cultura de aveia-preta. A utilização de propulsão pneumática não influenciou os resultados da $\mathrm{RP}$ e da $\mathrm{RT}$. Isso permite concluir que a curva de compressão do solo, a RP e a RT podem ser determinadas utilizando o equipamento desenvolvido neste estudo.

Termos de Indexação: ensaio de compressão uniaxial, pressão de preconsolidação, índice de compressão, resistência do solo à penetração, estresse tênsil.

\section{SUMMARY: DEVELOPMENT OF A PNEUMATIC CONSOLIDOMETER: COMPACTION MODELING, PENETROMETRY AND TENSILE STRENGTH OF SOIL AGGREGATES}

Soil compaction is one of the processes responsible for soil physical degradation that may result in the loss of sustainability of agricultural production. Therefore, it is important to have instrumental strategies to quantify soil physical properties that are influenced by soil compression and used to assess soil quality. The objectives of this study were to: (i) develop an inexpensive pneumatic consolidometer, (ii) evaluate its functionality by the study of the compressive behaviour of a sandy clay Rhodic Hapludox under no-tillage, (iii) evaluate the potential use of pneumatic propulsion to determine penetration resistance $(P R)$ and tensile strength of aggregates (TS) using the proposed consolidometer. Compression curves based on undisturbed soil sampled in and between rows under black oat were used to evaluate the soil compressive behaviour. Uniaxial compression tests were performed in these samples at a soil water content corresponding to a matric potential of -10 $\mathrm{kPa}$ and used to determine the compression index (CI) and preconsolidation pressure $\left(\sigma_{p}\right)$ and their correlations with other soil physical properties. PR of undisturbed samples of a sandy loam soil under citrus was determined. Aggregates from two Ultisols were used to determine TS in a hardsetting and a non-hardsetting horizons. Results showed that soil bulk density before the uniaxial compression test was higher $(p<0.05)$ in-between the black oat rows. The compression curve was sensitive to differences in soil structure between sampling positions, and $\sigma_{p}$ and CI indicated, respectively, higher load support and less susceptibility to compaction $(p<0.05)$ in-between the black oat rows. The use of pneumatic propulsion did not influence the results of PR and TS. Therefore, the soil compression curve, PR and TS can be determined with the equipment developed in this study.

Index terms: uniaxial compression test, preconsolidation pressure, compression index, soil resistance to penetration, tensile stress.

\section{INTRODUÇÃO}

A compactação é um dos processos que mais altera a estrutura do solo. Esse processo ocorre em um sistema tridimensional, induzido por estresses mecânicos comumente originados do tráfego de máquinas e da ação de implementos agrícolas (Flowers $\&$ Lal, 1998) e, ou, do pisoteio de animais (Bharati et al., 2002). Como resultado, a compactação do solo provoca o rearranjo dos agregados na matriz e a expulsão de ar, com decréscimo de seu espaço poroso total (Gupta \& Allmaras, 1987), por causa da transformação de poros de maiores diâmetros em menores (Dexter, 2004; Zhang et al., 2006), o que incrementa a densidade do solo (Gupta et al., 1989; Hill, 1990; Hakansson \& Voorhees, 1998). Isso leva à deterioração da qualidade física do solo, podendo limitar seu potencial produtivo agrícola (Kirkegaard et al., 1995; Beutler et al., 2006) e degradar a qualidade ambiental (Doran \& Parkin, 1994). 
A resistência do solo à redução de seu volume quando submetido a uma carga mecânica é definida como compressibilidade (Bradfort \& Gupta, 1986; Gupta \& Allmaras, 1987; Horn \& Lebert, 1994), a qual depende de fatores externos e internos. Os fatores externos são caracterizados pelo tipo, intensidade e frequência da força aplicada (Horn, 1988; Lebert \& Horn, 1991), enquanto os fatores internos se referem à história de tensão, teor de água, teor de matéria orgânica, textura, estrutura, densidade do solo inicial, dentre outros (Horn, 1988; McBride, 1989; Imhoff et al., 2004). Portanto, o comportamento compressivo do solo apresenta estreita relação com o sistema de manejo (Holtz \& Kovacs, 1981). Nesse contexto, alguns indicadores, como a pressão de preconsolidação e o índice de compressão, têm sido úteis para o planejamento mais adequado da execução de operações mecanizadas e a redução dos problemas de degradação física de solos agrícolas (Kondo \& Dias Junior, 1999; Silva et al., 2000; Dias Junior et al., 2005). Esses indicadores são obtidos da curva de compressão, que expressa a relação entre o logaritmo da pressão aplicada e a densidade do solo (ou índice de vazios) (Holtz \& Kovacs, 1981).

Geralmente, a curva de compressão do solo consiste em duas regiões: a reta de compressão virgem, sendo sua inclinação o índice de compressão (Terzaghi \& Peck, 1967); e a curva de compressão secundária, que corresponde às pressões aplicadas ao solo que não provocam sua compactação adicional (Holtz \& Kovacs, 1981). A pressão que separa essas duas regiões da curva de compressão do solo é conhecida como pressão de preconsolidação (Casagrande, 1936). A pressão de preconsolidação tem sido amplamente aceita como um indicador da história de tensão à qual o solo foi submetido no passado e de sua capacidade de suporte de carga (Veenhof \& McBride, 1996), ao passo que o índice de compressão é utilizado como um indicador da suscetibilidade do solo à compactação (Larson et al., 1980). Contudo, para gerar curvas de compressão do solo, é necessário utilizar um equipamento específico, denominado consolidômetro.

No Brasil, poucos consolidômetros têm sido produzidos, e os modelos importados, automatizados ou não, possuem elevado custo, o que limita a utilização do índice de compressão e da pressão de preconsolidação, bem como o estudo de suas relações com outros indicadores da qualidade física de solos agrícolas. Dessa forma, frequentemente, funções de pedotransferência têm sido utilizadas para estimar a pressão de preconsolidação e, ou, o índice de compressão a partir de determinações de atributos facilmente mensuráveis, como a textura e o teor de água no solo (Horn \& Fleige, 2003; Imhoff et al., 2004), a densidade do solo (McBride \& Joosse, 1996; Imhoff et al., 2004; Suzuki et al., 2008), a matéria orgânica (McBride \& Joosse, 1996), a resistência tênsil de agregados (RT) (Mosaddeghi et al., 2003), dentre outros. A pressão de preconsolidação também apresenta potencial para predizer as condições adequadas ao crescimento de plantas, devido à sua estreita relação com a resistência do solo à penetração (RP) (Römkens \& Miller, 1971; Culley \& Larson, 1987; Mosaddeghi et al., 2003; Dias Junior et al., 2004; Suzuki et al., 2008). Além disso, considerando a curva de compressão, é possível determinar o volume total de poros em função da densidade do solo. Isso permite identificar os níveis de pressão aplicada que podem reduzir a macroporosidade do solo a $0,1 \mathrm{~m}^{3} \mathrm{~m}^{-3}$ (Oliveira et al., 2003), considerada crítica ao crescimento de raízes (Vomocil \& Flocker, 1966).

Dessa forma, os objetivos deste trabalho foram: desenvolver um consolidômetro com propulsão pneumática e de baixo custo; avaliar sua funcionalidade mediante o estudo do comportamento compressivo de um Latossolo Vermelho distrófico de textura argilo-arenosa sob plantio direto; e demonstrar o potencial de utilização do sistema de propulsão pneumática nas determinações da RP, num Argissolo Vermelho-Amarelo distrófico de textura francoarenosa, bem como da RT, num Argissolo Acinzentado coeso e num Argissolo Amarelo não coeso.

\section{MATERIAL E MÉTODOS}

\section{Detalhes construtivos do consolidômetro}

O consolidômetro proposto foi desenvolvido no Laboratório de Física do Solo da Escola Superior de Agricultura "Luiz de Queiroz" (ESALQ), Piracicaba SP. O seu princípio de funcionamento consiste na utilização de um corpo-de-prova (amostra indeformada de solo), confinado lateralmente em anel volumétrico metálico e com livre drenagem nas extremidades superior e inferior, cujas superfícies são submetidas a incrementos sucessivos de pressão vertical (US Department of the Army, 1970). Para isso, foi desenvolvido um sistema pneumático que permite aplicar cargas instantâneas sobre o corpo-de-prova, com carregamentos axiais mantidos por tempos definidos em função da deformação vertical do solo. A compressibilidade do corpo-de-prova é determinada a partir da redução de sua altura, detectada por um dispositivo medidor de deslocamento linear: um relógio comparador eletrônico com capacidade de $12,7 \mathrm{~mm}$ e resolução de $0,01 \mathrm{~mm}$ (Figura 1A,c). O consolidômetro construído (Figura 1) e os componentes de seu sistema pneumático são caracterizados a seguir:

a) Um filtro de ar Norgren, série Excelon ${ }^{\circledR}$, modelo F72G-2GN-QD3, com capacidade de pressão até 17 bar (1.700 kPa) (Figura 1B,a), cuja finalidade é garantir maior segurança aos demais componentes pneumáticos, principalmente para as válvulas reguladoras de pressão e de fluxo de ar.

b) Um cilindro pneumático de duplo efeito e com amortecimento fixo (modelo RA/192000 - ISO 21287) (Figura 1A,b), acondicionado no interior do gabinete 
metálico. Esse atuador linear tem diâmetro do êmbolo e curso iguais a 100 e $50 \mathrm{~mm}$, respectivamente, e o deslocamento vertical de seu eixo transmite carga à amostra durante o ensaio de compressão axial.

c) Uma válvula reguladora de pressão de ar Norgren, modelo 11018-110 (Figura 1B,b), cuja função é controlar os carregamentos correspondentes às pressões entre 25 e $1.600 \mathrm{kPa}$. Sua faixa nominal de operação de pressão de ar é de 0,4 a 10 bar (40 a $1.000 \mathrm{kPa}$ ), sendo utilizado um manômetro eletrônico (Figura 1A,a) com capacidade máxima de 10 bar e resolução de 0,01 bar para medição da pressão de ar aplicada no cilindro pneumático. $\mathrm{O}$ manômetro fornece leituras em bar.

d) Uma válvula de fluxo multidirecional, marca Norgren, modelo X3 3637 02, tipo 5/3 vias, centro fechado, com acionamento manual por alavanca (Figura 1B,c). Essa válvula permite controlar o posicionamento vertical do eixo do cilindro pneumático.

e) Duas válvulas controladoras de fluxo de ar (marca Norgren, tipo unidirecionais) que permitem regular a velocidade de deslocamento do eixo do atuador linear, sendo uma localizada no interior do equipamento e conectada ao cilindro pneumático, com regulagem fixa e atuante no retorno do eixo do atuador à posição inicial (modelo C0SA01228), e outra (Figura 1B,d) com regulagens definidas pelo usuário e atuante na compressão da amostra (modelo T1000A2800).

Para calibrar o consolidômetro, foi estabelecida a relação entre a força $(\mathrm{F})$, isto é, a carga vertical transmitida ao corpo-de-prova, e a pressão de ar $\left(\mathrm{P}_{\mathrm{ar}}\right)$ aplicada no cilindro pneumático, ajustada manualmente na válvula reguladora (Figura 1B,b). A variação de $\mathrm{F}$ em função de diferentes níveis de $\mathrm{P}_{\mathrm{ar}}$ foi determinada por meio de uma célula de carga, com capacidade máxima de $750 \mathrm{kgf}$ e sensibilidade de $2 \mathrm{mV} / \mathrm{V}$, entreposta no lugar do corpo-de-prova e fixada na parte superior do consolidômetro. Os dados de calibração foram utilizados no ajuste da equação $\mathrm{F}=\left(a \mathrm{P}_{\mathrm{ar}}+b\right)$, em que $a$ e $b$ são o coeficiente angular e o intercepto, respectivamente. Dessa forma, foi possível estimar os valores de $\mathrm{P}_{\mathrm{ar}}$ correspondentes aos carregamentos no ensaio de compressão uniaxial considerando a

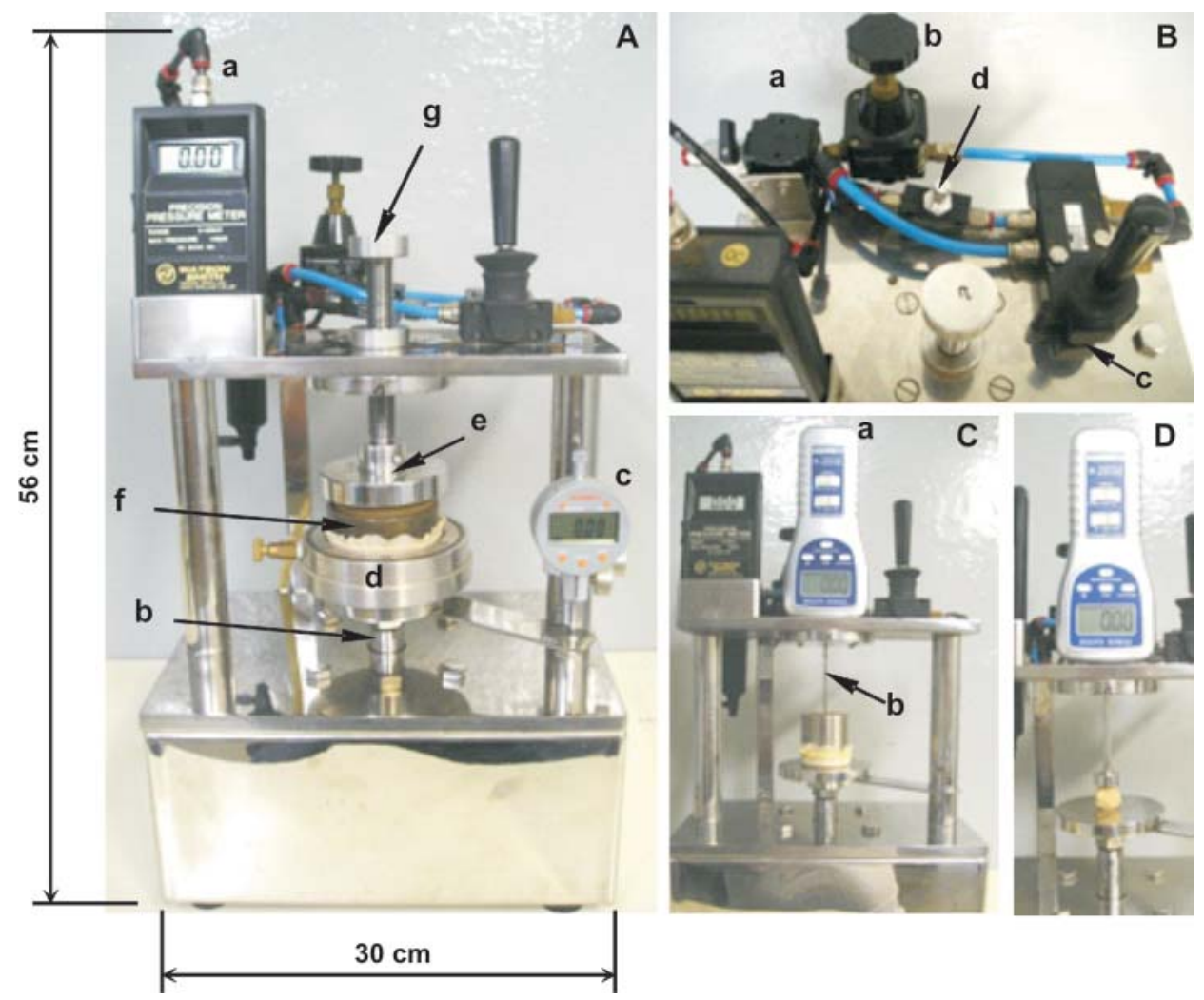

Figura 1. Consolidômetro pneumático com um corpo-de-prova (A,f) sob ensaio de compressão uniaxial. Detalhes: (A,a) manômetro; $(A, b)$ eixo do cilindro pneumático; $(A, c)$ indicador de deformação do corpode-prova; (A,d) e (A,e) suportes com as placas porosas inferior e superior, respectivamente, do dispositivo de transferência de pressão ao corpo-de-prova; (A,g) dispositivo de regulagem vertical; (B,a) filtro de ar; $(B, b)$ válvula reguladora de pressão; (B,c) válvula de fluxo multidirecional; (B,d) válvula controladora de fluxo; $(C, a)$ dinamômetro eletrônico; $(C, b)$ haste para penetrometria; e (D) eixo com placa metálica plana para ensaio de resistência tênsil de agregados. 
equação $\mathrm{F}=(\mathrm{P} \mathrm{A})$, em que $\mathrm{P}$ é a pressão gerada pela carga vertical aplicada na superfície de área $\mathrm{A}$, referente ao diâmetro do corpo-de-prova. Neste trabalho, ressalta-se que os níveis de $\mathrm{P}_{\text {ar }}$ foram expressos em bar, para facilitar seu monitoramento por meio de um manômetro (Figura 1A,a), e os de P, em $\mathrm{kPa}$, como comumente ocorre em ensaios de compressão uniaxial.

Alternativamente, foram desenvolvidos alguns acessórios que permitem a utilização de um dinamômetro eletrônico (Figura 1C,a) integrado ao consolidômetro. Dessa forma, pode ser acoplada ao dinamômetro uma haste de aço com extremidade cônica, para penetrometria (Figura 1C,b), ou um eixo com uma placa metálica plana, para ensaios de resistência tênsil de agregados de solo (Figura 1D). Sua montagem é relativamente simples e rápida, consistindo apenas na substituição dos dispositivos para ensaio de compressão uniaxial pelo dinamômetro e seus acessórios.

\section{Compressibilidade do solo}

O estudo foi desenvolvido em um solo classificado como Latossolo Vermelho distrófico (Embrapa, 2006) de textura argilo-arenosa (476, 44 e $480 \mathrm{~g} \mathrm{~kg}^{-1}$ de argila, silte e areia, respectivamente), localizado na Fazenda Experimental da Universidade Estadual de Ponta Grossa, Ponta Grossa, PR, e sob sistema de plantio direto há mais de 16 anos, com rotação das culturas soja, milho, feijão, trigo, aveia-preta, ervilhaca e tremoço. As dimensões da área experimental foram de 50 x $10 \mathrm{~m}$, e a amostragem correspondeu a uma linha e entrelinha ao centro da cultura de aveia-preta. Para cada posição de amostragem, na camada superficial entre 2,5 e $5,0 \mathrm{~cm}$, foram coletadas oito amostras indeformadas de solo, utilizando anéis volumétricos de $7,0 \times 2,5 \mathrm{~cm}$ de diâmetro e altura, respectivamente.

No laboratório, as amostras foram saturadas com água, por capilaridade, durante 48 h. Em seguida, foram submetidas ao potencial mátrico de $-10 \mathrm{kPa}$, utilizando câmaras de Richards (Klute, 1986). Após atingir o equilíbrio hidráulico, cada amostra foi pesada e submetida ao ensaio de compressão uniaxial, realizado mediante a aplicação sucessiva e contínua de pressões crescentes e estáticas de 25, 50, 100, 200, $300,400,600,800,1.000,1.300$ e $1.600 \mathrm{kPa}$. Cada pressão foi aplicada durante cinco minutos, seguindo o método descrito por Silva et al. (2000). A variação da altura da amostra de solo em função do carregamento aplicado foi registrada e utilizada nos cálculos de deformação do solo. Finalizado o ensaio de compressão uniaxial, as amostras foram secas em estufa a $105^{\circ} \mathrm{C}$, por $24 \mathrm{~h}$, para determinação da densidade do solo (Ds), segundo Blake \& Hartge (1986). O teor de água em cada amostra, imediatamente antes do ensaio, foi determinado pela razão entre as massas de água e de solo seco. A porosidade total foi estimada pela equação (1) e as variações do índice de vazios, da porosidade de aeração e do grau de saturação do solo, obtidos em função dos carregamentos aplicados, foram calculadas pelas eqs. (2), (3) e (4):

$$
\begin{gathered}
\text { PT }=1-\frac{\text { Dsi }}{\mathrm{Dp}} \\
\varepsilon=\frac{\mathrm{Dp}}{\mathrm{Ds}}-1 \\
\alpha=\mathrm{PT}-\theta \\
\mathrm{Gs}=\frac{\theta}{\mathrm{PT}} 100
\end{gathered}
$$

em que PT é a porosidade total $\left(\mathrm{m}^{3} \mathrm{~m}^{-3}\right)$; Dsi, a densidade do solo inicial $\left(\mathrm{Mg} \mathrm{m}^{-3}\right)$; $\mathrm{Dp}$, a densidade de partículas, com valor arbitrário de $2,6 \mathrm{Mg} \mathrm{m}^{-3} ; \varepsilon$, o índice de vazios $\left(\mathrm{m}^{3} \mathrm{~m}^{-3}\right) ; \alpha$, a porosidade de aeração $\left(\mathrm{m}^{3} \mathrm{~m}^{-3}\right) ; \theta$, o teor de água $\left(\mathrm{m}^{3} \mathrm{~m}^{-3}\right)$; e $\mathrm{Gs}$, o grau de saturação do solo (\%), sendo considerada a densidade da água igual a 1,0 $\mathrm{Mg} \mathrm{m}^{-3}$.

O ensaio realizado permitiu obter curvas de compressão, que consistem no índice de vazios do solo em função do logaritmo da pressão vertical aplicada $(\sigma)$ (Figura 2). Essas curvas foram ajustadas pelo método "spline cúbico", a partir dos procedimentos desenvolvidos por Imhoff et al. (2004) com o programa computacional Mathcad $^{\circledR}$ (Mathsoft, 2000), sendo gerados os gráficos das curvas de compressão do solo e de suas derivadas de primeira ordem, bem como estimados os valores do índice de compressão (IC) e da pressão de preconsolidação $\left(\sigma_{p}\right)$ para as duas posições de amostragem. Na primeira etapa, o algoritmo desenvolvido por Imhoff et al. (2004) calcula o ponto de máxima curvatura da curva de compressão, que corresponde ao valor mínimo de sua derivada de segunda ordem. Em etapas sucessivas, no ponto de máxima curvatura, o programa calcula: a reta tangente (Figura 2b); a reta paralela ao eixo das abscissas (Figura 2a); a bissetriz do ângulo formado entre as retas tangente e a paralela ao eixo das abscissas (Figura 2c); e o prolongamento da reta de compressão virgem (Figura 2d). Finalmente, a abscissa da interseção entre a bissetriz e o prolongamento da reta de compressão virgem é a $\sigma_{p}$ (Casagrande, 1936), e a inclinação dessa última reta corresponde ao IC.

\section{Novas aplicações para o sistema pneumático \\ Resistência do solo à penetração}

A avaliação da funcionalidade do equipamento proposto para determinações da resistência à penetração (RP) foi realizada em amostras indeformadas de solo em anéis volumétricos $(5 \mathrm{~cm}$ de diâmetro e altura). Para isso, foi selecionado um Argissolo Vermelho-Amarelo distrófico (Embrapa, 2006) de textura franco-arenosa (150, 66 e $784 \mathrm{~g} \mathrm{~kg}^{-1}$ de argila, silte e areia, respectivamente) cultivado com citros, localizado no campus da ESALQ, Piracicaba, 


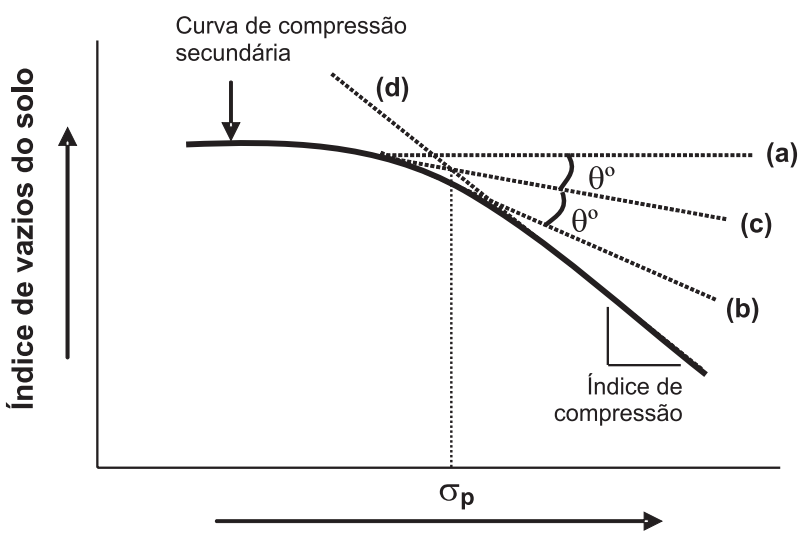

log da pressão vertical aplicada

Figura 2. Curva de compressão do solo e estimativa da pressão de preconsolidação $\left(\sigma_{p}\right)$ segundo o método de Casagrande (1936): (a) reta paralela ao eixo das abscissas no ponto de máxima curvatura; (b) reta tangente no ponto de máxima curvatura; (c) bissetriz do ângulo formado entre as retas (a) e (b); (d) reta de compressão virgem.

SP. Aleatoriamente, foram coletadas duas amostras indeformadas de solo na área experimental, sendo individualmente revestidas com filme de PVC. No laboratório, as amostras foram ajustadas ao volume de seu anel volumétrico, sendo colocada uma tela de náilon na extremidade inferior, e submetidas à saturação (por capilaridade) com água deionizada por 48 h. Depois, cobriu-se sua extremidade superior com papel, deixando-se secar ao ar (lentamente e com drenagem livre), a fim de obter um gradiente de teor de água entre as amostras. Em seguida, as amostras foram revestidas com filme de PVC e mantidas sob refrigeração $\left(5{ }^{\circ} \mathrm{C}\right.$ por $\left.30 \mathrm{~d}\right)$, para redistribuição interna da água.

Antes do ensaio de RP, as amostras foram pesadas em balança eletrônica com resolução de 0,01 g. Em seguida, acoplada ao dinamômetro, uma haste de aço teve sua extremidade cônica (ângulo de $60^{\circ}$ e diâmetro basal de $0,4 \mathrm{~cm}$ ) introduzida até $4,0 \mathrm{~cm}$ da superfície superior de cada amostra de solo, numa velocidade de valor nominal igual a $10 \mathrm{~mm} \mathrm{~min}^{-1}$ (Tormena et al., 1998), obtida via válvula controladora de fluxo (Figura 1B,d) submetida à pressão de ar de 8 bar (800 kPa), ajustada na válvula reguladora de pressão (Figura 1B,b). Imediatamente quando o cone da haste metálica começou a se deslocar, foi acionado o início da transferência dos dados de força (kgf) medidos para o computador. Para isso, foi utilizado um programa computacional fornecido pelo fabricante do dinamômetro, com protocolo de comunicação RS-232, ajustado para a frequência de uma medição por segundo, totalizando 240 medições por amostra de solo. Posteriormente, numa planilha eletrônica, cada medição de força foi relacionada com sua profundidade na amostra, calculada pelo produto da velocidade de deslocamento da haste de aço e o tempo de duração do ensaio. O conjunto de dados de força, obtido em cada amostra, foi transformado para pressão:

$$
\mathrm{RP}=\frac{\mathrm{Fg}}{\mathrm{A} 10^{6}}
$$

sendo RP expressa em MPa; F, a força medida (kgf); $\mathrm{g}$, a aceleração da gravidade $\left(\mathrm{m} \mathrm{s}^{-2}\right)$; e A, a área basal do cone $\left(\mathrm{m}^{2}\right)$.

Ao final do ensaio, foram determinados o teor de água gravimétrico, pela razão entre as massas de água e de solo seco, e a densidade do solo (Ds) (Blake \& Hartge, 1986). O teor de água volumétrico no solo ( $\theta)$ foi obtido pelo produto do teor de água gravimétrico e a Ds.

\section{Resistência tênsil de agregados}

O potencial de utilização do consolidômetro proposto para determinações da RT foi avaliado em agregados naturais de dois solos, localizados em uma área da Estação Experimental da Embrapa/CNPAT, em Pacajus, CE (Lima et al., 2005). Para comparação quanto à coesão, foram utilizados um Argissolo Acinzentado distrófico arênico coeso (PACd) e um Argissolo Amarelo distrófico arênico (PAd) (Embrapa, 2006), ambos sob cultivo de cajueiro anão e sob mata nativa, respectivamente, e localizados próximos entre si. As amostras do PACd e do PAd foram obtidas nos horizontes Bt na profundidade média de 1,17 e 1,51 m, respectivamente, cuja caracterização é apresentada no quadro 1. Em cada área experimental foi coletado um bloco indeformado de solo, com 15 × 22 × $7 \mathrm{~cm}$ de largura, comprimento e altura, respectivamente. Esses blocos foram revestidos com filme de PVC, acondicionados em caixas térmicas e transportados ao laboratório. Em seguida, os blocos foram manualmente destorroados em seus agregados naturais pela aplicação de uma força mínima necessária para separá-los pelos seus pontos de fraqueza. O diâmetro dos agregados foi classificado com o auxílio de duas peneiras, cujas respectivas aberturas de malha foram de 19,0 e 12,7 mm (Imhoff et al., 2002). Para secagem final e homogeneização do teor de água, esses agregados foram secos ao ar por $36 \mathrm{~h}$ e em estufa $\left(60^{\circ} \mathrm{C}\right.$ por $\left.24 \mathrm{~h}\right)$, sendo armazenados

Quadro 1. Caracterização granulométrica ${ }^{(1)}$ e matéria orgânica (MO) do Argissolo Acinzentado distrófico arênico coeso (PACd) e do Argissolo Amarelo distrófico arênico (PAd), conforme resultados obtidos por Lima et al. (2005)

\begin{tabular}{lccccc} 
Solo & Sistema de uso & Argila & Silte & Areia & MO \\
\hline & & \multicolumn{4}{c}{ g kg $^{-1}$} \\
\cline { 3 - 5 } PACd & Cultivo & 290 & 40 & 670 & 3,0 \\
PAd & Mata & 280 & 20 & 700 & 8,0
\end{tabular}

(1) Argila: < $2 \mu \mathrm{m}$; silte: $2-50 \mu \mathrm{m}$; areia: $50-2.000 \mu \mathrm{m}$. 
em sacos de papel até o momento da realização dos ensaios de RT. Foram utilizadas 30 repetições por área experimental.

As medições de $\mathrm{RT}$ foram realizadas em duas máquinas de ensaio: no equipamento proposto e em uma máquina manual de ensaios para dinamometria. Essa máquina é originalmente acionada por meio de uma manivela, que permite o deslocamento vertical de um dinamômetro durante a realização dos ensaios de RT, sendo já utilizada em outros trabalhos (Neves Junior, 2008; Almeida, 2008; Seben Junior, 2010). Entretanto, no Laboratório de Física do Solo da ESALQ, realizou-se a automatização do deslocamento do dinamômetro, visando obter uma velocidade constante de deslocamento igual a $1,55 \mathrm{~mm} \mathrm{~s}^{-1}$ (Figueiredo, 2010), para reduzir os erros sistemáticos da experimentação. No consolidômetro proposto, foi utilizada uma pressão de ar de 8 bar $(800 \mathrm{kPa})$, ajustada na válvula reguladora (Figura $1 \mathrm{~B}, \mathrm{~b})$, sendo a velocidade de deslocamento do eixo do cilindro pneumático de $0,03 \mathrm{~mm} \mathrm{~s}^{-1}$, obtida pelo ajuste da válvula controladora de fluxo (Figura 1B,d).

Previamente, em ambas as máquinas de ensaio, cada agregado de solo foi pesado em balança analítica e, em seguida, submetido ao ensaio de tensão indireta. Os agregados de solo foram individualmente colocados na posição mais estável entre duas placas metálicas: uma inferior, fixa à base da máquina de ensaio, e outra superior, móvel e ligada à extremidade da célula de carga do dinamômetro, com capacidade de $20 \mathrm{kgf}$. A força necessária à ruptura tênsil de cada agregado de solo foi obtida mediante a função "peak hold" do dinamômetro, que registra a força de maior intensidade antes da ruptura do agregado devido à compressão proporcionada pela placa móvel. As amostras foram pesadas em balança analítica e submetidas à secagem em estufa a $105^{\circ} \mathrm{C}$ por $48 \mathrm{~h}$, para determinação do teor de água residual médio dos agregados de solo. A RT foi calculada conforme Dexter \& Kroesbergen (1985):

$$
\mathrm{RT}=\frac{0,576 \mathrm{P}}{\mathrm{D}^{2} 10^{3}}
$$

sendo RT a resistência tênsil de agregados $(\mathrm{kPa})$; 0,576 , a constante de proporcionalidade da relação entre o estresse compressivo aplicado e o estresse tênsil gerado no interior do agregado; $\mathrm{P}$, a força aplicada (N); e D, o diâmetro efetivo do agregado (m).

O diâmetro efetivo do agregado foi calculado pela equação (Dexter \& Kroesbergen, 1985):

$$
\mathrm{D}=\mathrm{D}_{\mathrm{m}}\left(\frac{\mathrm{M}}{\mathrm{M}_{0}}\right)^{0,333}
$$

em que $\mathrm{D}_{\mathrm{m}}$ é o diâmetro médio dos agregados (m), definido pela média dos tamanhos da abertura das peneiras; M, a massa do agregado individual seco (g); e $\mathrm{M}_{\mathrm{o}}$, a massa média dos agregados secos (g).

\section{Análises estatísticas}

Os dados referentes aos índices obtidos a partir da curva de compressão do solo e as demais propriedades físicas envolvidas nos ensaios de compressão uniaxial foram submetidos à análise de variância, sendo as médias entre as posições de amostragem comparadas pelo teste $t(\mathrm{p}<0,05)$. Em cada amostra de solo, os dados de RP foram utilizados para gerar um gráfico de seu perfil de distribuição até 4,0 cm de profundidade, sendo calculadas as medidas de dispersão e de posição apenas para os $3 \mathrm{~cm}$ finais, visando eliminar o efeito da bordadura (Bradford, 1986). Os dados de RT, para ambos os solos e equipamentos, foram submetidos à análise de variância e ao teste $\mathrm{F}(\mathrm{p}<0,05)$. Foi aplicado o teste de Shapiro-Wilk para avaliar a normalidade da distribuição dos dados submetidos à análise de variância.

\section{RESULTADOS E DISCUSSÃO}

A utilização de curva de calibração apresenta como vantagem a simplificação dos cálculos da relação entre a pressão de ar regulada no consolidômetro e a pressão atuante na superfície da amostra de solo durante o ensaio de compressão uniaxial (Figura 3). Isso é importante porque quantificar as perdas de carga em um sistema pneumático nem sempre é fácil. Para os quatro primeiros pontos da curva de calibração, equivalentes à pressão de ar de 0,$15 ; 0,24 ; 0,38$; e 0,63 bar, houve pequena divergência de linearidade em relação aos demais dados. Esse fato se deve à válvula reguladora de pressão, que possui faixa de operação entre 0,4 e 10 bar, o que dificulta manter um ajuste mais preciso para baixos valores de pressão. Se for considerado o ajuste da curva de calibração apenas para os quatro primeiros pontos, é obtida a seguinte equação: $\hat{y}=74,641 x-4,315\left(R^{2}=0,997\right)$. A partir dessa equação, para uma amostra com diâmetro de $0,07 \mathrm{~m}$, é constatado que os carregamentos correspondentes a 25 e $50 \mathrm{kPa}$ apresentam erros desprezíveis $(\approx 2,1$ e $0,4 \mathrm{kPa}$, respectivamente) em relação àqueles estimados pelo modelo ajustado mostrado na figura 3 , indicando que a curva de calibração obtida para a faixa de pressões de ar entre 0,15 e 7,9 bar (15 e $790 \mathrm{kPa}$ ) foi adequada para os ensaios de compressão uniaxial.

\section{Compressibilidade do solo}

A variabilidade da densidade do solo inicial (Dsi) nas amostras indeformadas utilizadas nos ensaios de compressão uniaxial apresentou similaridade entre as posições de amostragem - fato justificado pela magnitude do coeficiente de variação (Quadro 2). Entretanto, as médias da Dsi foram diferentes $(\mathrm{p}<0,05)$, evidenciando os contrastes de estrutura do solo entre as posições de amostragem. Por outro lado, embora a pressão de preconsolidação $\left(\sigma_{p}\right)$ tenha sido 


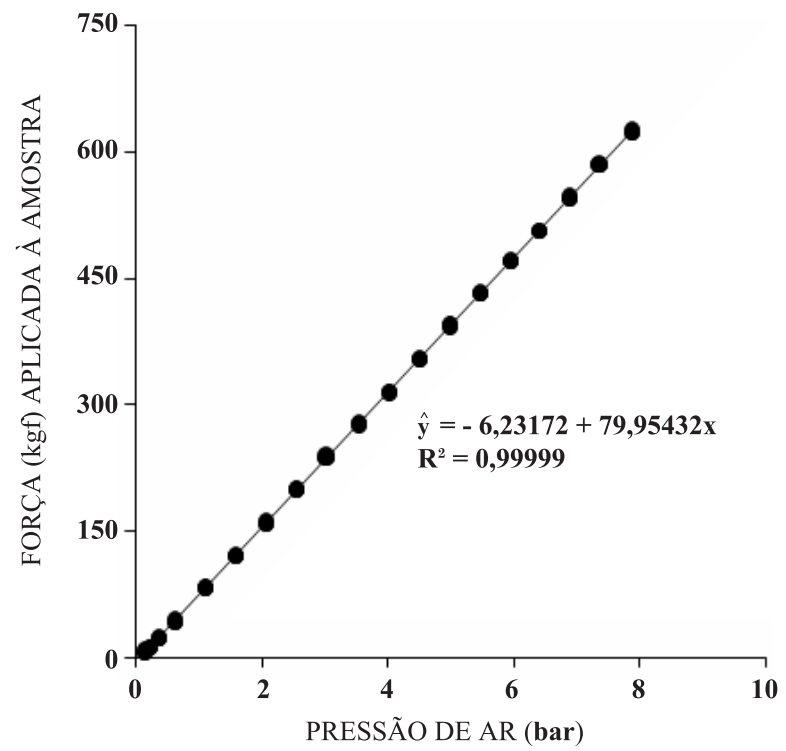

Figura 3. Curva de calibração do consolidômetro: variação da força aplicada à amostra de solo em função da pressão de ar no cilindro pneumático. $\mathrm{N}=90$ para cada pressão manométrica.

maior $(p<0,05)$ para a entrelinha da cultura, os valores de densidade do solo final (Dsf) não diferiram entre as posições de amostragem $(p>0,05)$. Desse modo, a partir do momento em que os carregamentos se tornaram maiores que a $\sigma_{\mathrm{p}}$, isto é, maior que a capacidade de suporte de carga, a deformação adicional (plástica) do solo destruiu sua estrutura (Dias Junior \& Pierce, 1996; Silva et al., 2000; Dias Junior et al., 2005). Assim, os valores de Dsf, obtidos sob máximo estresse $(1.600 \mathrm{kPa})$, foram similares entre as amostras independentemente da posição de amostragem. Ressalta-se que os valores do índice de compressão (IC), que expressa a suscetibilidade à compactação, e de deformação (Def) confirmaram a maior compressibilidade do solo para a linha da cultura. Isso se deveu, provavelmente, à eliminação da história de tensão decorrente da mobilização do solo na época do plantio, o que diminuiu sua compactação em relação à entrelinha da cultura (Baver et al., 1972).

As curvas de compressão do solo (Figura 4a) suavemente apresentaram forma tipo "S" para as diferentes posições de amostragem, o que indica desvios de linearidade em relação à reta de compressão virgem em altos valores de carregamentos no ensaio de compressão uniaxial (Baumgartl \& Kock, 2004). Desse modo, quando o estresse aplicado foi elevado o bastante para produzir essa forma de curva, suas derivadas de primeira ordem (-d $/$ /dlog $\sigma)$ apresentaram mudança abrupta, caracterizada por decréscimo acentuado a partir do ponto de máximo valor na figura $4 \mathrm{~b}$, indicando mais claramente o momento inicial dos desvios de linearidade (Tang et al., 2009). Esses desvios induzem a erros nas estimativas das propriedades físicas relacionadas ao comportamento compressivo do solo, como a $\sigma_{\mathrm{p}}$ e o IC, considerando o algoritmo utilizado neste trabalho (Imhoff et al., 2004); portanto, os dados obtidos dessa parte da curva de compressão não foram utilizados.

Os fatores que promoveram a forma tipo "S" das curvas de compressão (Figura 4a) estão relacionados às mudanças na porosidade do solo. As figuras $4 \mathrm{c}, \mathrm{d}$ respectivamente mostram a expulsão de ar e de água dos poros das amostras decorrentes da redução de seu volume em resposta aos estresses aplicados nos ensaios de compressão uniaxial. Segundo Tang et al. (2009), durante a compressão das amostras inicialmente há aumento de pressão de ar nos poros e, subsequentemente, de água. Dessa forma, enquanto o decréscimo do volume de poros contendo ar foi dominante, a inclinação das curvas -de/dlogo versus logo (Figura 4b) dependeu somente da estrutura do solo,

Quadro 2. Resumo estatístico das propriedades físicas ${ }^{(1)}$ do Latossolo Vermelho distrófico utilizado no ensaio de compressão uniaxial para cada posição de amostragem. $(\mathrm{N}=8)$

\begin{tabular}{|c|c|c|c|c|c|c|}
\hline Índice estatístico & Dsi & Dsf & Def & $\theta$ & $\sigma_{p}$ & IC \\
\hline & \multirow{2}{*}{\multicolumn{2}{|c|}{$\longrightarrow \mathrm{Mg} \mathrm{m}^{-3}$}} & $\mathrm{~mm}$ & $\mathrm{~m}^{3} \mathrm{~m}^{-3}$ & $\mathrm{kPa}$ & \\
\hline & & & Linha da cultura & & & \\
\hline Mínimo valor & 0,83 & 1,49 & 9,58 & 0,25 & 33,45 & 0,59 \\
\hline Máximo valor & 0,99 & 1,65 & 11,62 & 0,36 & 82,30 & 0,77 \\
\hline Desvio-padrão & 0,051 & 0,063 & 0,581 & 0,033 & 16,684 & 0,062 \\
\hline Coeficiente de variação (\%) & 5,49 & 3,99 & 5,61 & 11,18 & 24,81 & 9,32 \\
\hline \multirow[t]{2}{*}{ Média $^{(2)}$} & $0,93 \mathrm{~B}$ & $1,57 \mathrm{~A}$ & $10,36 \mathrm{~A}$ & $0,30 \mathrm{~A}$ & $67,25 \mathrm{~B}$ & $0,66 \mathrm{~A}$ \\
\hline & & & Entrelinha da cultu & & & \\
\hline Mínimo valor & 1,02 & 1,51 & 6,35 & 0,25 & 108,37 & 0,41 \\
\hline Máximo valor & 1,16 & 1,58 & 8,46 & 0,37 & 172,22 & 0,64 \\
\hline Desvio -padrão & 0,056 & 0,024 & 0,826 & 0,036 & 20,103 & 0,081 \\
\hline Coeficiente de variação (\%) & 5,14 & 1,56 & 11,16 & 11,64 & 14,85 & 15,85 \\
\hline Média $^{(2)}$ & $1,09 \mathrm{~A}$ & $1,54 \mathrm{~A}$ & $7,41 \mathrm{~B}$ & $0,31 \mathrm{~A}$ & $135,39 \mathrm{~A}$ & $0,51 \mathrm{~B}$ \\
\hline
\end{tabular}

(1) Dsi, densidade do solo inicial; Dsf, densidade do solo final; Def, deformação do solo; $\theta$, teor de água no solo, $\sigma$, pressão de preconsolidação; IC, índice de compressão do solo. ${ }^{(2)}$ Médias seguidas de letras iguais, na coluna, não diferem entre si pelo teste $t$ a $5 \%$. 
PRESSÃO DE AR (bar)
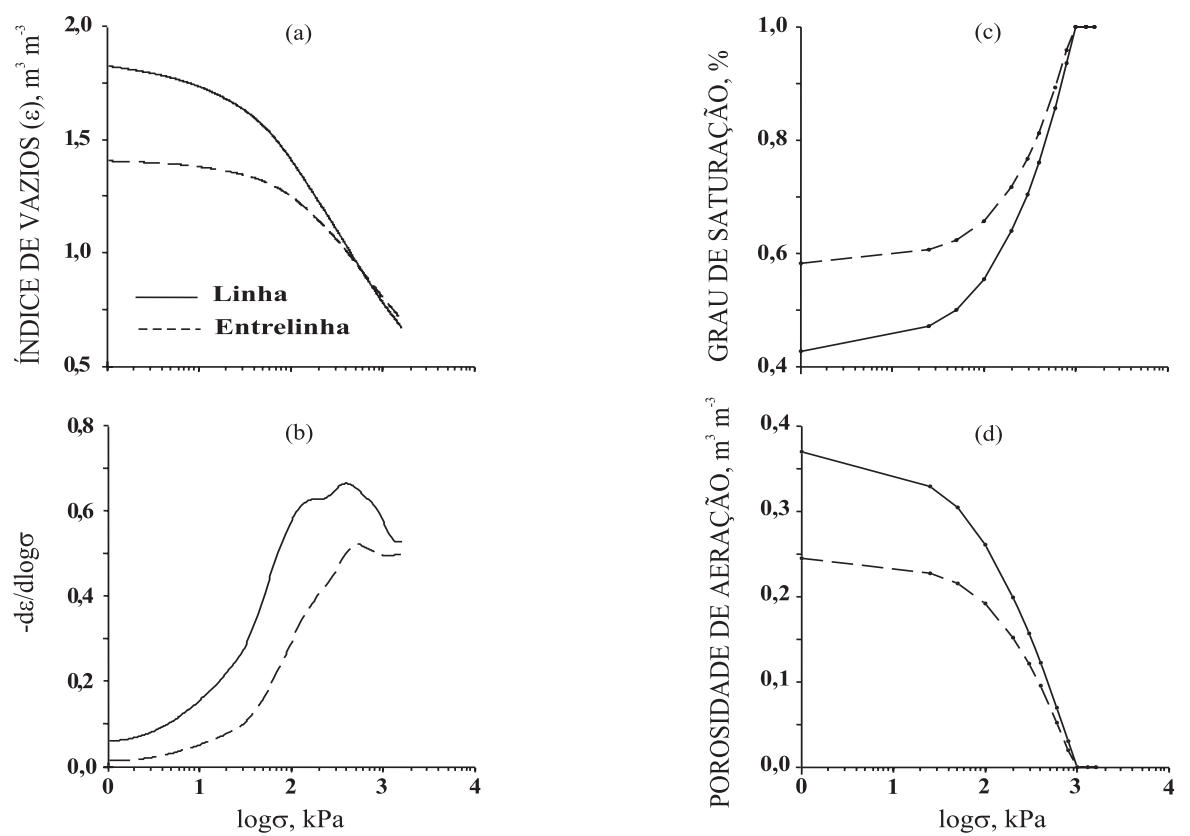

Figura 4. Curva de compressão do solo (a), sua primeira derivada (b) e variações do grau de saturação (c) e da porosidade de aeração (d) em função da pressão aplicada $(\sigma)$ num Latossolo Vermelho distrófico de textura argilo-arenosa sob plantio direto, correspondente à camada de $2,5-5,0 \mathrm{~cm}$, nas posições linha $\mathrm{e}$ entrelinha da cultura da aveia-preta. $(N=8)$.

visto que o ar flui mais facilmente que a água. Por outro lado, quando a redução do volume de poros com água se tornou dominante, a inclinação dessas curvas passou a ser abruptamente menor que o caso anterior, em razão da necessidade de maior estresse para balancear as forças capilares e ocorrer drenagem. Assim, pelo fato de a redução da porosidade promover decréscimos da permeabilidade do solo ao ar (Horn et al., 1995) e da condutividade hidráulica (Dexter et al., 2004; Zhang et al., 2006), o tempo necessário para dissipação da pressão gerada nos poros pode ter sido maior que cinco minutos (duração de cada carregamento), sendo determinante para obtenção das curvas de compressão com a forma tipo "S".

As relações entre as variáveis obtidas da curva de compressão (Figura 5) apresentaram distribuição normal dos dados, conforme indicado pelo teste de Shapiro-Wilk, além de todos os valores de $\mathrm{R}^{2}$ serem altamente significativos ( $p<0,0001)$. Observa-se que, quanto maior a Dsi, menor é a deformação adicional do solo (Figura 5a), maior a $\sigma_{\mathrm{p}}$ (Figura 5b) e menor o IC (Figura 5d), o que concorda, por exemplo, com Horn (1988), Silva et al. (2000, 2002), e Suzuki et al. (2008), visto que as amostras avaliadas apresentam a mesma composição granulométrica e não diferem $(\mathrm{p}>0,05)$ entre si quanto ao teor de água (Quadro 2). Nesse contexto, pode-se afirmar que o comportamento compressivo do solo foi alterado principalmente pela Dsi. Isso ocorre porque as partículas do solo, individualizadas (cristais) ou agrupadas (domínios), são capazes de separar-se e movimentar-se em relação às outras, sendo esse movimento limitado pelas forças de fricção e pelas ligações entre as partículas. Dessa forma, quanto mais denso o solo e mais intrincado o seu arranjo de partículas, menor é o espaço poroso disponível à movimentação e maior a força de fricção entre as partículas sólidas. Assim, o deslocamento e o rearranjo de partículas sólidas para posições mais próximas são restringidos com o incremento da densidade do solo (Vepraskas, 1984; Paz \& Guérif, 2000).

Os ajustes dos coeficientes das regressões lineares para a $\sigma_{\mathrm{p}}$ e o IC apresentaram valores associados a Dsi iguais a 357,14 e -1,03, respectivamente (Figuras 5b,d), sendo concordantes com as faixas de valores obtidas em outros trabalhos: para a $\sigma_{p}$, as estimativas variaram de 114 a 508 (Canarache et al., 2000; Imhoff et al., 2004; Saffih-Hdadi et al., 2009) e, para o IC, de -0,12 a -1,59 (Salire et al., 1994; Imhoff et al., 2004; Saffih-Hdadi et al., 2009). Resumidamente, as amplitudes das faixas de valores obtidas por esses autores resultam dos diferentes procedimentos utilizados para a compressão das amostras de solo. Ademais, as relações entre a deformação do solo e a $\sigma_{\mathrm{p}}$ e o IC (Figuras 5c,e) apresentaram comportamentos distintos, ou seja, quanto maior sua compressibilidade, menor capacidade de suporte de carga e maior suscetibilidade à compactação lhe são conferidas, o que concorda com Suzuki et al. (2008). Portanto, os resultados experimentais obtidos neste trabalho evidenciam que o desempenho do consolidômetro foi satisfatório para 

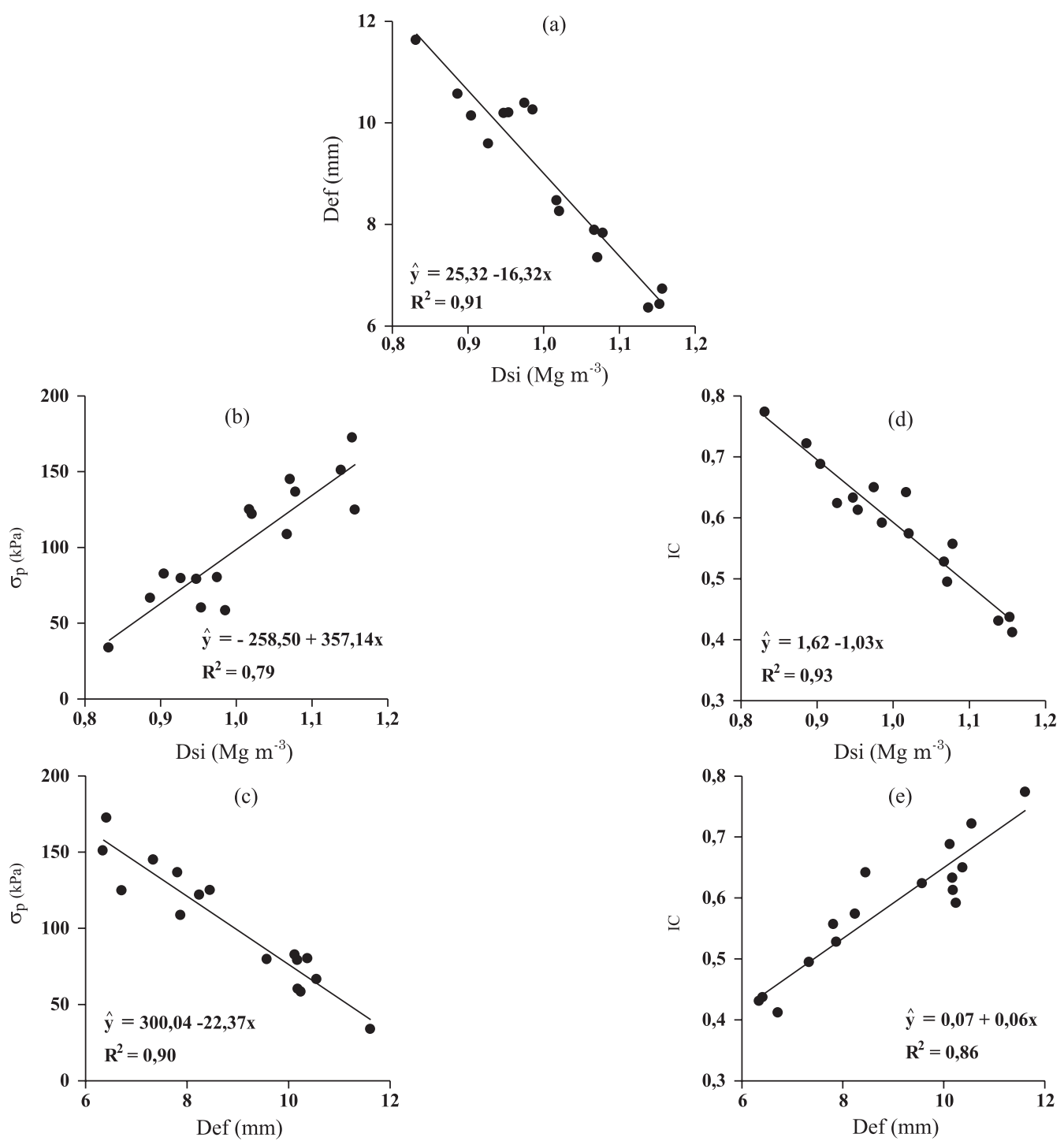

Figura 5. Relações entre a densidade do solo inicial (Dsi) e a deformação do corpo-de-prova ao final do ensaio de compressão uniaxial (Def) (a), a pressão de preconsolidação $\left(\sigma_{\mathrm{p}}\right)(\mathrm{b})$ e o índice de compressão (IC) (d), e relações entre a Def e a $\sigma_{\mathrm{p}}$ (c) e o IC (e), considerando o conjunto de amostras $(\mathrm{N}=16) \mathrm{de}$ um Latossolo Vermelho distrófico de textura argilo-arenosa. Todos os valores de $\mathbf{R}^{2}$ foram significativos $(\mathrm{p}<0,0001)$.

ensaios de compressão uniaxial, uma vez que produziu resultados coerentes com a literatura.

\section{Novas aplicações para o sistema pneumático}

O potencial de utilização do equipamento de propulsão pneumática nas determinações da resistência do solo à penetração $(\mathrm{RP})$ e da resistência tênsil de agregados (RT) também foi avaliado para verificar a possibilidade de determinações de maior número de indicadores da qualidade físico-estrutural de solos com um único equipamento.

A distribuição dos valores de RP, em cada amostra de solo, é mostrada na figura 6 . Houve diferença de apenas 8,0 s no tempo total do ensaio entre as amostras devido ao momento de finalização da transferência dos dados de força para o computador, procedimento dependente da intervenção do usuário, mas não comprometeu os resultados obtidos. Foram observadas medidas crescentes de RP para os primeiros milímetros; em geral, houve tendência à estabilização a partir de $0,5 \mathrm{~cm}$ de profundidade, com notável ausência de valores discrepantes ao longo das medições. Isso significa que os dados obtidos apresentaram distribuição de valores típicos e condizentes com as argumentações de Bradford (1986) sobre o final do efeito da bordadura nos valores de RP, que comumente ocorre entre 0,5 e 1,0 cm da superfície da amostra de solo. Ademais, quando a densidade do solo (Ds) foi de $1,65 \mathrm{Mg} \mathrm{m}^{-3}$ e o teor de água ( $\theta$ ) igual a $0,16 \mathrm{~m}^{3} \mathrm{~m}^{-3}$, o valor médio de RP correspondeu a 1,86 $\mathrm{MPa}$, com coeficiente de variação (CV) de 3,63\%. 
RESISTÊNCIA À PENETRAÇÃO (MPa)

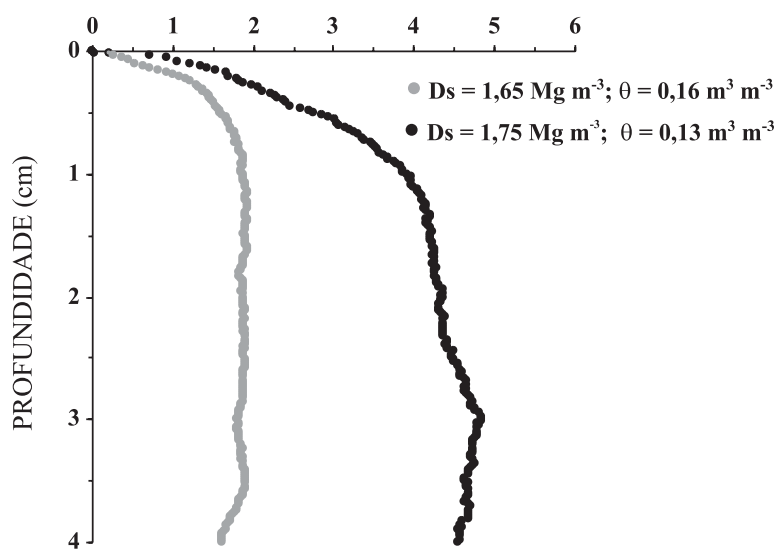

Figura 6. Distribuição da resistência à penetração em duas amostras indeformadas $(5 \mathrm{~cm}$ de diâmetro e altura) de um Argissolo Vermelho-Amarelo distrófico, textura franco-arenosa, para diferentes condições de teor de água $(\theta)$ e densidade do solo $(\mathrm{Ds})$. $(\mathrm{N} \approx 240)$.

Para a outra amostra $\left(\mathrm{Ds}_{\mathrm{s}}=1,75 \mathrm{Mg} \mathrm{m}^{-3}\right.$ e $\theta=$ $0,13 \mathrm{~m}^{3} \mathrm{~m}^{-3}$ ), o valor médio de RP foi de 4,46 MPa e o CV igual a 5,39 \%. Aumento de RP com o decréscimo do $\theta$ é um processo que ocorre devido ao incremento no estresse efetivo (Snyder \& Miller, 1985), sendo intensificado positivamente pela Ds, que promove maior força de fricção entre as partículas e o aumento da coesão do solo (Vepraskas, 1984). Esses resultados evidenciam que a qualidade dos dados de RP obtidos utilizando propulsão pneumática foi satisfatória.

Para os dados de RT, a diferença entre os valores da média e da mediana não foi acentuada (Quadro 3). Isso indica que provavelmente os dados foram distribuídos simetricamente em torno dessas medidas de posição - fato confirmado pelo teste de ShapiroWilk. Por sua vez, os valores da amplitude ou do coeficiente de variação (CV) mostram que essa propriedade física apresenta variabilidade entre média $(15 \leq \mathrm{CV}<50 \%)$ e alta $(\mathrm{CV} \geq 50 \%)$, segundo a classificação proposta por Warrick \& Nielsen (1998). Isso justifica uma amostragem mais intensa, mas também requer um método analítico adequado para não somar-se à variabilidade espacial a influência da velocidade de compressão dos agregados de solo. $\mathrm{O}$ método utilizado neste trabalho permite eliminar a interferência do usuário na velocidade de deslocamento do dinamômetro durante os ensaios, o que justifica tornar o equipamento proposto apropriado para determinações de RT.

A análise de variância dos dados indicou que a RT não foi influenciada pelos tipos de máquinas de ensaio utilizadas $(\mathrm{F}=0,07 ; \mathrm{p}>0,796)$. Em relação aos outros fatores em estudo, a interação (Solo*Máquina de ensaio) foi não significativa, apresentando valor do teste de Fischer nulo e com $\mathrm{p}>0,954$. Apenas o fator (Solo) foi altamente significativo $(\mathrm{F}=148,74$; $\mathrm{p}<0,0001)$. Isso indica que os valores médios de RT apresentaram comportamento similar aos obtidos por outros autores. Lima et al. (2005) e Almeida (2008) estudaram o mesmo Argissolo Acinzentado distrófico arênico coeso utilizado neste trabalho e encontraram valores médios de RT de 76,65 e 62,91 kPa, respectivamente. Ainda, Lima et al. (2005) encontraram para o mesmo Argissolo Amarelo distrófico arênico um valor médio de RT de 18,88 kPa. Pode-se inferir que as diferenças entre os resultados obtidos pelos autores citados e os do presente trabalho (Quadro 3) são decorrentes sobretudo da variabilidade dos pontos experimentais. Dessa forma, embora o ar seja altamente compressível e possa influir na velocidade de deslocamento do eixo do atuador linear do consolidômetro, a propulsão pneumática foi adequada para determinações de RT na condição de pressão de ar utilizada (800 kPa).

\section{CONCLUSÕES}

1. O consolidômetro pneumático desenvolvido neste trabalho obteve desempenho satisfatório nos ensaios de compressão uniaxial e permitiu estimar a curva

Quadro 3. Resumo estatístico da resistência tênsil de agregados do Argissolo Acinzentado distrófico arênico coeso (PACd) e do Argissolo Amarelo distrófico arênico (PAd) determinada utilizando uma máquina de ensaio para dinamometria (controle) e um consolidômetro pneumático (equipamento proposto), cujas velocidades de ensaio foram de 1,55 e $0,03 \mathrm{~mm} \mathrm{~s}^{-1}$, respectivamente. CV: coeficiente de variação. $(\mathrm{N}=30)$

\begin{tabular}{|c|c|c|c|c|c|c|}
\hline Solo & Mínimo valor & Máximo valor & Mediana & Média & Desvio-padrão & $\mathbf{C V}$ \\
\hline & \multirow{2}{*}{\multicolumn{6}{|c|}{$\begin{array}{l}\text { - } \mathrm{kPa} \\
\text { uina de ensaio para dinamometria }\end{array}$}} \\
\hline & & & & & & \\
\hline PACd & 28,10 & 83,36 & 59,60 & 60,74 & 13,529 & 22,27 \\
\hline \multirow[t]{2}{*}{ PAd } & 4,40 & 60,19 & 25,10 & 26,84 & 16,974 & 63,25 \\
\hline & \multicolumn{6}{|c|}{ Consolidômetro pneumático } \\
\hline PACd & 34,55 & 84,93 & 60,96 & 60,17 & 14,611 & 24,28 \\
\hline PAd & 5,54 & 63,39 & 22,20 & 25,95 & 15,858 & 61,11 \\
\hline
\end{tabular}


de compactação, o índice de compressão e a pressão de preconsolidação em amostras indeformadas de solo, possibilitando detectar com elevada acurácia os diferentes graus de consolidação, bem como as distintas histórias de tensão da estrutura do solo em função da posição de amostragem.

2. A resistência do solo à penetração e a resistência tênsil de agregados mostraram valores coerentes com os disponíveis na literatura, sendo potencialmente possível determiná-las utilizando o equipamento proposto.

3. O custo relativamente mais baixo do consolidômetro proposto é um atrativo ao desenvolvimento de estudos mais detalhados sobre o potencial de utilização da propulsão pneumática nas determinações de resistência do solo à penetração e de resistência tênsil de agregados.

\section{LITERATURA CITADA}

ALMEIDA, B.G. Métodos alternativos de determinação de parâmetros físicos do solo e uso de condicionadores químicos no estudo da qualidade do solo. Piracicaba, Escola Superior de Agricultura "Luiz de Queiroz", Universidade de São Paulo, 2008. 103p. (Tese de Doutorado)

BAUMGARTL, T. \& KOCK, B. Modeling volume change and mechanical properties with hydraulic models. Soil Sci. Soc. Am. J., 68:57-65, 2004.

BAVER, L.D.; GARDNER, W.H. \& GARDNER, W.R. Soil physics. 4.ed. New York, John Wiley, 1972. 498p.

BEUTLER, A.N.; CENTURION, J.F.; CENTURION, M.A.P.C. \& SILVA, A.P. Efeito da compactação na produtividade de cultivares de soja em Latossolo Vermelho. R. Bras. Ci. Solo, 30:787-794, 2006.

BHARATI, L.; LEE; K.H.; ISENHART; T.M. \& SCHULTZ, R.C. Soil water infiltration under crops, pasture, and established riparian buffer in Midwest USA. Agrof. Syst., 56:249-257, 2002.

BLAKE, G.R. \& HARTGE, K.H. Bulk density. In: KLUTE, A., ed. Methods of soil analysis. 2.ed. Madison, American Society of Agronomy/Soil Science Society of America, 1986. Part 1. p.363-375.

BRADFORD, J.M. Penetrability. In: KLUTE, A., ed. Methods of soil analysis. 2.ed. Madison, American Society of Agronomy/Soil Science Society of America, 1986. Part 1. p.463-478.

BRADFORD, J.M. \& GUPTA, S.C. Compressibility. In: KLUTE, A., 2.ed. Methods of soil analysis. 2.ed. Madison, American Society of Agronomy, Soil Science Society of America, 1986. Part 1. p.279-492.

CANARACHE, A.; HORN, R. \& COLIBAS, I. Compressibility of soils in a long term field experiment with intensive deep ripping in Romania. Soil Tillage Res., 56:185-196, 2000 .
CASAGRANDE, A. Determination of the preconsolidation load and its practical significance. In: INTERNATIONAL CONFERENCE ON SOIL MECHANICS AND FOUNDATION ENGINEERING, 1936, Cambridge. Proceedings... Cambridge, Harvard University, 1936. p.60-64.

CULLEY, J.L.B. \& LARSON, W.E. Susceptibility to compression of a clay loam Haplaquoll. Soil Sci. Soc. Am. J., 51:562-567, 1987.

DEXTER, A.R. Soil physical quality: Theory, effects of soil texture, density, and organic matter, and effects on root growth: Part 1. Geoderma, 120:201-214, 2004.

DEXTER, A.R. \& KROESBERGEN, B. Methodology for determination of tensile strength of soil aggregates. J. Agric. Eng. Res., 31:139-147, 1985.

DEXTER, A.R.; CZYZ, E.A. \& GATE, O.P. Soil structure and the saturated hydraulic conductivity of subsoils. Soil Tillage Res., 79:185-189, 2004.

DIAS JUNIOR, M.S. \& PIERCE, F.J. O processo de compactação do solo e sua modelagem. R. Bras. Ci. Solo, 20:175-182, 1996.

DIAS JUNIOR, M.S.; LEITE, F.P.; LASMAR JÚNIOR, E. \& ARAUJO JUNIOR, C.F. Traffic effects on the soil preconsolidation pressure due to eucalyptus harvest operations. Sci. Agric., 62:248-255, 2005.

DIAS JUNIOR, M.S.; SILVA, A.R.; FONSECA, S. \& LEITE, F.P. Método alternativo de avaliação da pressão de preconsolidação por meio de um penetrômetro. R. Bras. Ci. Solo, 28:805-810, 2004.

DORAN, J.W. \& PARKIN, T.B. Defining and assessing soil quality. In: DORAN, J.W.; COLEMAN, D.C.; BZEDICEK, D.F. \& STEWART, B.A., eds. Defining soil quality for a sustainable environment. Madison, Soil Science Society of America, 1994. p.3-21. (Special Publication, 35)

EMPRESA BRASILEIRA DE PESQUISA AGROPECUÁRIA EMBRAPA. Centro Nacional de Pesquisas de Solos. Sistema brasileiro de classificação de solos. 2.ed. Rio de Janeiro, Embrapa Solos; Brasília, Sistema de Produção de Informação, 2006. 306p.

FLOWERS, M.D. \& LAL, R. Axle load and tillage effects on soil physical properties and soybean grain yield on a Molic Ochraqualf in Northwest. Soil Tillage Res., 48:21-35, 1998.

FIGUEIREDO, G.C. Avanços metodológicos e instrumentais em física do solo. Piracicaba, Escola Superior de Agricultura "Luiz de Queiroz", Universidade de São Paulo, 2010. 163p. (Tese de Doutorado)

GUPTA, S.C. \& ALLMARAS, R.R. Models to assess the susceptibility of soils to excessive compaction. Adv. Soil Sci., 6:65-100, 1987.

GUPTA, S.C.; HADAS, A. \& SCHAFER, R.L. Modeling soil mechanical behavior during compaction. In: LARSON, W.E.; BLAKE, G.R.; ALLMARAS, R.R.; VOORHEES, W.B. \& GUPTA, S.C., eds. Mechanics and related process in structured agricultural soils. Dordrecht, Kluwer Academic Publishers, 1989. p.137-152. 
HAKANSSON, I. \& VOORHEES, W.B. Soil compaction. In: LAL, R.; BLUM, W.H.; VALENTINE, C. \& STEWART, B.A., eds. Methods for assessment of soil degradation. Boca Raton, CRC Press, 1998. p.167-179.

HILL, R.L. Long-term conventional and no-tillage effects on selected soil physical properties. Soil Sci. Soc. Am. J., 54:161-166, 1990.

HOLTZ, R.D. \& KOVACS, W.D. An introduction to geotechnical engineering. Englewood Cliffs, Prentice-Hall, 1981. 733p.

HORN, R. Compressibility of arable land. Catena, 11:53-71, 1988.

HORN, R. \& FLEIGE, H. A method for assessing the impact of load on mechanical stability and on physical properties of soils. Soil Tillage Res., 73:89-99, 2003.

HORN, R.; DOMZAL, H.; SLOWINSKA-JURKIEWICZ, A. \& van OUWERKERK, C. Soil compaction processes and their effects on the structure of arable soils and the environment. Soil Tillage Res., 35:23-36, 1995.

HORN, R. \& LEBERT, M. Soil compactability and compressibility. In: SOANE, B.D. \& van OUWERKERK, C., eds. Soil compaction in crop production. Amsterdam, Elsevier, 1994. p.45-69.

IMHOFF, S.; SILVA, A.P. \& DEXTER, A.R. Factors contributing to the tensile strenght and friability of Oxisols. Soil Sci. Soc. Am. J., 66:1656-1661, 2002.

IMHOFF, S.; SILVA, A.P. \& FALLOW, D. Susceptibility to compaction, load support capacity and soil compressibility of Hapludox. Soil Sci. Soc. Am. J., 68:17-24, 2004.

KIRKEGAARD, J.A.; MUNNS, R.; JAMES, R.A.; GARDNER, P.A. \& ANGUS, J.F. Reduced growth and yield of wheat with conservation cropping II: Soil biological factors limit growth under direct drilling. Aust. J. Soil Res., 46:75-88, 1995.

KLUTE, A. Water retention: Laboratory methods. In: KLUTE, A., ed. Methods of soil analysis. Madison, American Society of Agronomy/Soil Science Society of America, 1986. Part. 1. p.635-662.

KONDO, M.K. \& DIAS JUNIOR, M.S. Compressibilidade de três Latossolos em função da umidade e uso. R. Bras. Ci. Solo, 23:211-218, 1999.

LARSON, W.E.; GUPTA, S.C. \& USECHE, R.A. Compression of agricultural soils from eight soil orders. Soil Sci. Soc. Am. J., 44:450-457, 1980.

LEBERT, M. \& HORN, R. A method to predict the mechanical strength of agricultural soils. Soil Tillage Res., 19:275286, 1991.

LIMA, H.V.; SILVA, A.P.; ROMERO, R.E. \& JACOMINE, P.T.K. Comportamento físico de um Argissolo Acinzentado Coeso no Estado do Ceará. R. Bras. Ci. Solo, 29:33-40, 2005.

MATHSOFT. Mathcad professional reference manual. Cambridge, 2000. 180p

McBRIDE, R.A. Estimation of density-moisture-stress functions from uniaxial compression of unsaturated, structured soils. Soil Tillage Res., 13:383-397, 1989.
McBRIDE, R.A. \& JOOSSE, P.J. Overconsolidation in agricultural soils: II. Pedotransfer functions for estimating preconsolidation stress. Soil Sci. Soc. Am. J., 60:373-380, 1996.

MOSADDEGHI, M.R.; HEMMATB, A.; HAJABBASIA, M.A. \& ALEXANDROUC, A. Pre-compression stress and its relation with the physical and mechanical properties of a structurally unstable soil in central Iran. Soil Tillage Res., 70:53-64, 2003.

NEVES JUNIOR, A.F. Qualidade física de solos com horizonte antrópico (Terra Preta de Índio) na Amazônia Central. Piracicaba, Escola Superior de Agricultura "Luiz de Queiroz", Universidade de São Paulo, 2008. 93p. (Tese de Doutorado)

OLIVEIRA, G.C.; DIAS JUNIOR, M.S.; CURI, N. \& RESCK, D.V.S. Compressibilidade de um Latossolo Vermelho argiloso de acordo com a tensão de água no solo, uso e manejo. R. Bras. Ci. Solo, 27:773-781, 2003.

PAZ, A. \& GUÉRIF, J. Influence of initial packing density, water content and load applied during compaction on tensile strength of dry soil structural units. Adv. Geoecol., 32:22-31, 2000.

RÖMKENS, M.J.M. \& MILLER, R.D. Predicting root size and frequency from one-dimensional consolidation data - A mathematical model. Plant Soil, 35:237-248, 1971.

SAFFIH-HDADI, K.; DÉFOSSEZ, P.; RICHARD, G.; CUI, Y.J.; TANG, A.M. \& CHAPLAIN, V. A method to predict the soil susceptibility to compaction of surface layers as function of water content and bulk density. Soil Tillage Res., 105:96-103, 2009.

SALIRE, E.V.; HAMMEL, J.E. \& HARDCASTLE, J.H. Compression of intact subsoils under short-duration loading. Soil Tillage Res., 31:235-248, 1994.

SEBEN JUNIOR, G.F. Resistência tênsil de um Latossolo Vermelho eutrófico sob sequências de culturas em semeadura direta. Jaboticabal, Universidade Estadual Paulista “Julio de Mesquita Filho", 2010. 88p. (Tese de Mestrado)

SILVA, V.R.; REINERT, D.J. \& REICHERT, J.M. Susceptibilidade à compactação de um Latossolo Vermelho-Escuro e de um Podzólico Vermelho-Amarelo. R. Bras. Ci. Solo, 24:239-249, 2000.

SILVA, V.R.; REINERT, D.J.; REICHERT, J.M. \& SOARES, J.M. Fatores controladores da compressibilidade de um Argissolo Vermelho-Amarelo distrófico arênico e de um Latossolo Vermelho distrófico típico. I Estado inicial de compactação. R. Bras. Ci. Solo, 26:1-8, 2002.

SNYDER, V.A. \& MILLER, R.D. Tensile strength of unsaturated soils. Soil Sci. Soc. Am. J., 49:58-65, 1985.

SUZUKI, L.E.A.S.; REINERT, D.J.; REICHERT, J.M. \& LIMA, C.L.R. Estimativa da susceptibilidade à compactação e do suporte de carga do solo com base em propriedades físicas de solos do Rio Grande do Sul. R. Bras. Ci. Solo, 32:963973, 2008.

TANG, A.; CUI, Y.; ESLAMI, J. \& DÉFOSSEZ, P. Analysing the form of the confined uniaxial compression curve of various soils. Geoderma, 148:282-290, 2009. 
TERZAGHI, K. \& PECK, R.B. Soil mechanics in engineering practice. 2.ed. New York, John Wiley \& Sons, 1967. $729 \mathrm{p}$.

TORMENA, C.A.; SILVA, A.P. \& LIBARDI, P.L. Caracterização do intervalo hídrico ótimo de um Latossolo Roxo sob plantio direto. R. Bras. Ci. Solo, 22:573-581, 1998.

US DEPARTMENT OF THE ARMY. Laboratory soils testing. Washington, Army Corps of Engineers, 1970. 406p. (Engineer Manual, EM 1110-2-1906).

VEENHOF, D.W. \& MCBRIDE, R.A. Overconsolidation in agricultural soils: I. Compression and consolidation behavior of remolded and structured soils. Soil Sci. Soc. Am. J., 60:362-373, 1996.
VEPRASKAS, M.J. Cone index of loamy sands as influenced by pore size distribution and effective stress. Soil Sci. Soc. Am. J., 48:1220-1225, 1984.

VOMOCIL, J.A. \& FLOCKER, W.J. Effect of soil compaction on storage and movement of soil, air and water. Trans. Am. Soc. Agric. Eng., 4:242-246, 1966.

WARRICK, A.W. \& NIELSEN, D.R. Spatial variability of soil physical properties in the field. In: HILLEL, D. Environmental soil physics. New York, Academic, 1998. p.655-675.

ZHANG, S.; GRIP, H. \& LOVDAHL, L. Effect of soil compaction on hydraulic properties of two loess soils in China. Soil Tillage Res., 90:117-125, 2006. 